\title{
Corneal endothelial changes in patients wearing soft contact lens
}

\author{
Mustafa Duran*a, Volkan Yeter ${ }^{\mathrm{b}}$, Osman Sayına, Hakkı Birincia ${ }^{\mathrm{a}}$ İnci Güngör ${ }^{\mathrm{a}}$ \\ ${ }^{a}$ Department of Ophthalmology, Medical Faculty, Ondokuz Mayls University, Samsun, Turkey \\ ${ }^{b}$ Mengücek Gazi Education and Research Hospital, Erzincan, Turkey
}

ARTICLE INFO

ABSTRACT

\section{Article History}

Received

$10 / 11 / 2012$

Accepted $\quad 05 / 01 / 2013$

\section{* Correspondence to:}

Mustafa Duran

Department of Ophthalmology,

Medical Faculty,

Ondokuz Mayıs University,

Samsun, Turkey

e-mail: drmduran19@hotmail.com

\section{Keywords:}

Contact lens

Endothelial cell

Polymegathism

Pleomorphism
We aimed to compare the cornea thickness and corneal endothelial parameters of young myopic individuals regularly wearing soft silicon hydrogel contact lens for at least one year with those of control group. Central cornea thickness was determined with Galilei Dual-Scheimplug Analyzer by performing anterior segment scanning to the both eyes of young myopic individuals wearing soft contact lens regularly for more than one year and those never worn contact lens before (control group). Full thickness corneal scanning was performed using confocal microscope after administration of topical anesthesia. Endothelial count, polymegathism and pleomorphism values were determined via automatic endothelial analysis. Mann Whitney-U test was used for comparison of the groups. Of the 16 individuals wearing contact lens, 3 were male, 13 were female. The mean contact lens wearing time was 3.5 years (between 1 and 8 years). Of the 26 individuals in the control group, 8 were female, 18 were male. No statistically significant difference was observed between contact lens wearing and control groups in terms of age, refraction, central corneal thickness, pleomorphism and endothelial cell count whereas polymegathism was the only significant parameter between groups $(\mathrm{p}=0.021)$. Endothelial polymegathism was more common in individuals wearing silicon hydrogel soft contact lens than those in control group. The use of silicon hydrogel soft contact lens may cause alterations in corneal endothelial cell structure in the long period.

J. Exp. Clin. Med., 2013; 30:27-29

(C) 2013 OMU

\section{Introduction}

Contact lenses are the optical devices primarily used to correct refractive errors. They can be divided in two groups as hard and soft contact lenses depending on the material used. The first mention of contact lenses was made by Leonardo Da Vinci in his work "Codex Of The Eye", published in 1508 (Hofstetter and Graham, 1953). The first corneal lenses were produced in 1940's with the discovery of polymethylmethacrylate (PMMA) material. PMMA is a plastic material that is impermeable to oxygen. Afterwards gas-permeable hard lens materials were discovered and the first rigid gas-permeable (RGP) materials have been used as contact lenses. In 1950's, hydroxythylmethacrylate (HEMA), the first soft contact lens material, was discovered and the first soft contact lenses produced. These first materials are hydrogel and have been used for many years. Hydrogel materials involve oxygen and water evenly and have high level of oxygen transmission. New-generation contact lenses manufactured from silicone hydrogel $(\mathrm{SH})$ material which has became available from 90's, make a breakthrough with their high oxygen permeability (Barr, 2005).

In literature, studies involving the use of contact lenses made from both hydrogel and SH and examining endothelial cell density and structure are available.

It has long been known that the use of contact lenses may lead to various changes in tear layer, conjunctiva and cornea depending on oxygen-permeability of lenses. Contact lensinduced hypoxia and hypercapnia-induced lactate increase and corneal edema caused by acidosis are considered as the reasons (Holden et al., 1985; Leung et al., 2011).

Contact lenses may lead to giant papillary conjunctivits, upper limbic keratoconjunctivitis, allergic and toxic conjunctivitis in conjunctiva; limbal hyperemia, limbal neovascularisation, vascularized limbal keratitis in limbus as well increase in tear volume, decrease in tear break-up time, stromal deposits and endothelial changes in tear film layer (Doughty et al., 2005; Lee et al., 2012). Some of these changes may recur after stopping contact lens use depending on the contact lens wearing time (Sibug et al., 1991).

In this study, we aimed to compare the cornea thickness and corneal endothelial parameters of young myopic individuals regularly wearing $\mathrm{SH}$ soft contact lens for at least one year with those of control group. 


\section{Materials and methods}

Forty-two young myopic patients examined at the Department of Ophthalmology at Ondokuz Mayis University Hospital between December 2009 and March 2010 were included in the study. The patients with systemic disease and corneal pathology and those underwent eye surgery were excluded from study. The mean age of participants was 24 years (1837).

Central corneal thickness (CCT) was determined via Galilei Dual-Scheimpflug Analyzer (Ziemer Group, Port, Switzerland) by performing anterior segment scanning to the both eyes of the patients. While scanning, the patient sat in a comfortable position letting patient's chin and forehead lean against the device. The patients were asked to look straight so that the horizontal line become tangent to the corneal epithelium and then the measurements were determined by adopting the ones approved by device. Those having low reliability were measured again after a few minutes.

Topical anesthesia was administered in cornea for confocal microscopy measurements. After placing the patient's forehead and chin against the device, the patients were asked to look straight. Transparent tear gel was applied to the edge of confocal microscope (Nidek Confoscan4) to be contact with the cornea. The probe of confocal microscope was manually operated by a lever so that the probe can correspond to the patient's cornea. Full-thickness corneal scan was performed. Endothelial cell count, pleomorphism and polymegathism values were determined via automatic endothelium analysis program.

Age, refraction, CCT, endothelial count, pleomorphism and polymegathism parameters were compared stastistically using the Mann Whitney-U test.

\section{Results}

The patient group consisted of 16 individuals wearing contact lens. Of the patients, 3 were male and 13 were female. The mean age was 24 years (19-25). The average length of contact lens wearing was 3.5 years (1-8). The mean spherical refractive error of contact lens wearers was $-3.69 \pm 1.25 \mathrm{D}$.

Control group included 26 individuals who were not wearing contact lens. Of these, 18 were male and 8 were female. The mean age was 24 years $(18-37)$. The mean spherical refractive error of control group was $-3.87 \pm 1.25 \mathrm{D}$.

All the participants were young myopic individuals. No statistically significant difference was observed between contact lens wearers and control group in terms of age, refraction, CCT, endothelial cell count and pleomorphism $(\mathrm{p}=0.378$; $\mathrm{p}=0.486 ; \mathrm{p}=0.424 ; \mathrm{p}=0.128 ; \mathrm{p}=0.087$ and $\mathrm{p}=0.180$ respectively). Polymegathism was the only significant difference between the groups $(p=0.021)$. Our study has revealed that endothelial polymegathism was more common in individuals wearing soft contact lens for at least one year in comparison with control group.

\section{Discussion}

The corneal endothelium is a single layer of hexagon-shaped cells (about 70-80\%) lining the inner surface of the cornea. The number of endothelial cells in newborns is greater and decreases with age. In young adults, there are approximately
2800-3500 endothelial cells per $\mathrm{mm}^{2}$. Endothelial cells do not proliferate. Cell density is rather stable from age 20 through approximately age 50 years and decrease with age (Yee et al., 1985). The number of cells decreases after the age of sixty on a yearly basis with a ratio of $0.6 \%$ (Bourne et al., 1997).

Coefficient of variation (CV) is defined as the standard deviation of average cell area divided by its mean cell area. It should be below 0.30 in normal cornea. Increase in cell size in conjunction with increase in this ratio is called "polymegathism". "Pleomorphism" is defined as the changes in the shapes of cells due to endothelial damage (Rao et al., 1979; Phillips et al., 2005; ). These parameters and corneal thickness are the biological indicators used to assess endothelial function.

Several studies have shown that long-term contact lens use leads to alteration in endothelial morphology. In their study conducted in 1970's, Zantos and Holden specified that the use of contact lens lead to endothelial bleb formation (Zantos and Holden, 1977). In the studies conducted in 1985, it was purported that endothelial bleb formation occurs in response to acidosis induced by epithelial hypoxia (Schoessler et al.,1982; Holden et al., 1985). These studies (high water content hydrogel lens were used) showed reduction in epithelial oxygen uptake and significant differences in endothelial polymegathism. Having this condition frequent in hard PMMA and hydrogel contact lens wearers and rare in soft hydrogel lens users suggest that hypoxia is the main cause in the formation of these changes. Several researchers have reported that cell density did not change despite these morphological changes (Bourne et al., 2001). Lee et al.'s (2001) study involving endothelial changes in soft contact lens wearers (for less than 5 years, 5-10 years, more than 10 years) showed increase in polymegathism in all contact lens wearers; increase in polymegathism and pleomorphism in contact lens wearers for more than 6 years; and decrease in endothelial cell density depending on contact lens wearing period.

Sheng and Bullimore (2007) investigated the factors responsible for morphological changes in the corneal endothelium (age, race, contact lens wearing duration, degree of myopia) and determined that endothelial cell density was significantly affected by age and race whereas age and duration of contact lens use have a significant effect on endothelial polymegathism. In a study investigating $\mathrm{CCT}$ and endothelial changes in diabetic patients wearing or not wearing contact lens and normal healthy individuals, it was indicated that CCT is greater in diabetic patients as well as there is an increase in polymegathism in contact lens wearers regardless of contact lens wear (Leem et al., 2011).

The results of this study are consistent with those of previous studies in literature. Our study revealed that having young and healthy participants in the patient and control group is a significant factor affecting the difference in CCT and the number of endothelial cells. Although if contact lens wearing time was not too long, significant increase in polymegathism in contact lens wearing group was observed. This result suggests that silicone hydrogel soft contact lens may lead to endothelial damage due to hypoxia as compared to other materials. Long-term studies involving the use of silicon hydrogel soft contact lens are needed. 


\section{REFERENCES}

Barr, T.J., 2005. History and development of contact lenses. In: Bennet, S.E.,Weissman, A.B. Clinical contact lens practice. Lippincott Williams \&Wilkins. Section 1, chapter 1, 1-10.

Bourne, W.M., Nelson L.R., Hodge, D.O., 1997. Central corneal endothelial cell changes over a ten- year period. Invest. Ophtalmol. Vsi. Sci. 38, 779-782.

Bourne, W.M., 2001. The effect of long-term contact lens wear on the cells of the cornea. Clao J. 27, 225-230.

Doughty, M.J., Aakre, B.M., Ystenaes, A.E., Svarverud, E., 2005. Short-term adaptation of the human corneal endothelium to continuous wear of silicone hydrogel (lotrafilcon A) contact lenses after daily hydrogel lens wear. Optom. Vis. Sci. 82, 473-480.

Hofstetter, H.W., Graham, R., 1953. Leonardo and contact lenses. Am J Optom Arch Am Acad Optom. 30, 41-44.

Holden, B.A., Sweeney, D.F., Vannas, A., Nilsson, K.T., Efron, N., 1985. Effects of long-term extended contact lens wear on the human cornea. Invest. Ophtalmol. Vis. Sci. 26, 1489-1501.

Lee, S.Y., Kim, Y.H., Johnson, D., Mondino, B.J., Weismann, B.A., 2012. Contact lens complications in an urgent-care population: The University of California, Los Angeles, contact lens study. Eye Contact Lens. 38, 49-52.

Lee, J.S., Park, W.S., Lee, S.H., Oum, B.S., Cho, B.M., 2001. A comparative study of corneal endothelial changes induced by different durations of soft contact lens wear. Graefes Arch. Clin. Exp. Ophthalmol. 239, 1-4.

Leem, H.S., Lee, K.J., Shin, K.C., 2011. Central corneal thickness and corneal endothelial cell changes caused by contact lens use in diabetic patients. Yonsei Med. J. 52, 322-325.

Leung, B.K., Bonanno, J.A., Radke, C.J., 2011. Oxygen-deficient metabolism and corneal edema. Prog. Retin. Eye Res. Nov. $30,471-492$.

Phillips, C., Laing, R., Vee, R., 2005. Specular microscopy. In: Krachmer JH, Mannis MJ, Holland EJ, eds. Cornea. 2nd ed. Vol 1. Philadelphia: Elsevier/Mosby: 261-281.

Rao, G.N., Shaw, E.L., Arthur, E.J., Aquavella, J.V., 1979. Endothelial cell morphology and corneal de turgescence. Ann. Ophthalmol. 11, 885899.

Schoessler, J.P., Woloschak, M.J., Mauger, T.F., 1982. Transient endothelial changes produced by hydrophilic contact lenses. Am. J.Optom. Physiol. Opt. 59, 764-765.

Sheng, H., Bullimore, M.A., 2007. Factor affecting corneal endothelial morphology. Cornea Jun. 26, 520-525.

Sibug, M.E., Datiles, M.B. 3rd., Kashima, K., McCain, L., Kracher, G., 1991. Specular microscopy studies on the corneal endothelium after cessation of contact lens wear. Cornea. 10, 395-401.

Yee, R.W., Matsuda, M., Schultz, R.O., Edelhauser, H.F., 1985. Changes in the normal corneal endothelial cellular pattern as a function of age. Curr. Eye Res. 4, 671-678.

Zantos, S.G., Holden, B.A., 1977. Transient endothelial changes soon after wearing soft contact lenses. Am. J. Optom. Phsiol.Opt. 54, 856858. 